\title{
Uzbek as a Second Language: How Digital Technologies May Influence and Enhance it's Teaching
}

\author{
Aziza Mashrabbekova
}

\author{
Associate Professor, Hankuk University of Foreign Studies
}

\begin{abstract}
The subject matter of this paper is a discussion of the application of the new technologies to the teaching of Uzbek language learning and its methodological principles in particular institutions of higher learning like the universities. While the paper can address any language, in our case, the Uzbek language teaching in South Korea is the problem statement. It will be argued that the integration of new media into Uzbek language learning is a necessary step ensuring the acquisition of the kind of language skills and competencies needed for living and working in the knowledge society. A lot has been written on Uzbek language but no postulations have been made regarding the use of digital technologies in its teaching.
\end{abstract}

It is our presupposition that innovative use of such technologies in Uzbek language will lead to more flexibility in the content and organisation of learning; new media must be looked at not simply in terms of traditional selfstudy materials but rather in terms of tools for learning. New information and communication technologies and their role in language learning processes are the topic of this paper, but constructivism as the appropriate paradigm for language learning in the coming millennium will also be discussed. In addition, the paper proposes a typology and an evaluation of technology-enhanced materials for language learning, and presents a few examples.

New technologies have become the predominant influence on the way we live and work at the beginning of the new millennium. Some view the changes effected by global networks and information technologies with some apprehension. Others consider the innovative potential of world-wide co-operation via e-mail and internet as well as unprohibited access to information and digital resources by means of telecommunications and other forms of electronic publication to be of benefit for both the professional and the educational world,(Donath,2014).

\section{BACKGROUND}

Uzbekistan is undergoing tremendous changes. Such changes are linked with challenges which need to be met not just by business and industry but even more so by educational institutions at all levels as we already pointed out. New technologies as tools of almost any trade also need to be exploited in order to initiate changes in the way we teach and learn Uzbek language. A principled approach is needed in order to translate the potential of new technologies into new methodological approaches and changing organisational frameworks for the learning and acquisition of any subject. This is true even more for the learning of foreign languages, as language competencies and intercultural skills will more than ever be part of the key qualifications needed to live and work in the knowledge society Johns, 2010).

Consequently, the principles of the knowledge society in terms of its basic characteristics and the resulting challenges for (language) learning need to be discussed. New information and communication technologies and their role in Uzbek language learning processes are the topic of this study, but its initial focus will be an assessment of constructivism as the appropriate paradigm for Uzbek language learning in the coming millennium. Also, Papert's concept of constructionism will be discussed as a possible basis for putting theory into practice and defining a set of criteria for assessing different kinds of models and materials with regard to using new technologies in language learning. A discussion of new technologies and their potential cannot be restricted to a mere description of technical features or existing courseware and software tools,(Jonassen, \& Reeves,1996).

In addition to the social context, the theoretical principles and the methodological framework for materials development and the implementation of technology-enhanced Uzbek language learning scenarios need to be addressed. Following a discussion of the aspects mentioned so far, new 
information and communication technologies will be discussed in an overview and an assessment of existing applications in language learning. In addition, a typology of technology-enhanced materials for language learning will be proposed and examples of good practice referred to in order to show how new technologies can contribute to the innovation of language learning. Key factors with regard to this are the flexibility and authenticity of content and of the learning process itself. The study will conclude by discussing a few perspectives concerning future trends in TELL (Technology Enhanced Language Learning). These concern developments both on the technological and theoretical levels.

\section{LANGUAgE LEARNING AND CONSTRUCTIVISM}

Language learning has often be described as one of the most impressive mental operations of the human mind in view of the complexity of grammatical structures, the size of the mental lexicon, and the multiple functionality learners of any language are confronted with (e.g. Schwarz, 1992: 102). As a result, much controversy has arisen as to how a language can best be learned. Various theories of learning and cognition have influenced numerous approaches to language learning. In the past, scenarios built around acts of learning as opposed to processes of acquisition have dominated foreign language learning for a long time. Knowledge construction as a further aspect has only recently been added to the concepts discussed, but cognitive approaches had already begun to focus on building a learner's experiences and providing challenging learning tasks which can function as ,,intellectual scaffolding " (Roblyer et al., 2014) to help learners learn and progress through the different stages of a curriculum.

However, purely cognitivist theories are now being challenged by an approach which is not solely based on the findings of SLA (second language acquisition) research. In addition, this approach constructivism - is fully integrated into cognitive science, constructivist philosophy, neurology and biology as well as computer science. This approach ,perceives students as active learners who come to ... lessons already holding ideas ... which they use to make sense of everyday experiences. ... Such a process is one in which learners actively make sense of the world by constructing meaning. " (Scott, 2009: 4) Briefly put, such an approach regards active learning in terms of knowledge construction rather than traditional instruction as essential for the development of a coherent conceptual framework in a learner's mind, much needed in order to be able to cope with the mental challenges posed by the knowledge society.

Learning is viewed as an active, creative, and socially interactive process and knowledge is regarded as something children must construct and less like something that can be transmitted or transferred (e.g. Florin, 1990). Learning based on constructivist principles will allow learners to tap into resources and acquire knowledge rather than force them to function as recipients of instruction. Such approaches are meeting with growing approval and are regarded by many educational thinkers as a suitable theoretical framework for the language learning environment of the future as well as for the development of appropriate technology enhanced materials for the learning of foreign languages. It also means that making use of new technologies in language learning simply in the format of computer-based instruction packages with traditional grammar and vocabulary drills is not the best way of exploiting their real potential for innovation. Unfortunately, the majority of materials available to date follow a traditional, often even behaviourist drill and tutorial paradigm, which - quite understandably - leads a number of colleagues to reject the use of technology enhanced courseware.

Innovation by means of new technologies in language learning needs to search for other kinds of applications and follow more accepted models of learning. As far as foreign language learning is concerned, research into the processes of language learning and acquisition suggests that mere training in structural (grammatical) and vocabulary knowledge will not result in real linguistic competence and language proficiency. However, apart from basic communicative competencies, favoured in the communicative classroom of the 80 s, strategies of language processing and learning competence as well as language awareness are regarded as an essential part of the overall aims of any language curriculum. The basic principles and aims of language learning can be visualised by the following graph.

Such competencies, often discussed in the context of learner autonomy, are of utmost importance for language learning. Therefore, the constructivist paradigm is seen as an important methodological basis for a real innovation in foreign language learning. Within this paradigm, new technologies need to be exploited in such a way that the acquisition of communicative competence as well as language 
awareness and learning competence is ensured. Language learning as well as learning in general should be described as an interactive, dynamic process, in which new knowledge is most fruitfully acquired when learners are placed in a situation where they can explore sources and resources rather than in a context of mere formal instruction.

In such a scenario, learners combine new information with previous factual (declarative) and procedural knowledge and draw new conclusions from this process. Such a process-oriented approach to learning will not simply lead to a better understanding of linguistic facts (e.g. structure and vocabulary) and more effective acquisition of language proficiency; it will also lead to more learning competence as well as language awareness. These are the issues that need to be considered when looking at the use (fulness) of new technologies in foreign language learning.

\section{CONSTRUCTIVISM AND CONSTRUCTIONISM}

The question remains, however, of how the theoretical framework discussed above can be put into practice. i.e. how the principle of "learning without being taught" as proposed by Piaget (Papert,1980) can be integrated into a technology enhanced learning environment of the future? Within the scope of this study a full discussion of this issue is not possible, but a few issues need to be touched upon briefly, (Papert, 1991: 3)

Consequently, the trick to a successful transfer of constructivist theory onto a constructionist (possibly technology-enhanced) platform can be described as finding appropriate tasks which get the learner "engaged in the construction of something shareable“. One way of doing this is by means of problem-solving tasks, and tasks that encourage hypothesis formation and validation. Consequently, constructionism puts much emphasis on task-based learning. Also, constructionism favours play and experimentation, involving self-structured and self-motivated processes of learning. Both declarative and procedural knowledge need to be developed, thus adding to and increasing the cognitive apparatus of the learner, constant cognitive growth and cognitive flexibility being of the utmost importance for living and learning in the knowledge society. As far as a rich and rewarding technology-enhanced learning environment is concerned, Florin (1990) proposes the creation of information landscapes, of virtual towns, or intellectual amusement parks, an intriguing metaphor for the learning material for the future. Some of the more recent materials are beginning to follow such a line of thought, when translating adventure games or similar edutainement formats into language learning software.

As far as learning materials are concerned, an additional option for turning theory into practice is the use of so-called cognitive tools, particularly when using new technologies in language learning (Jonassen\& Reeves, 1996).

Typical and often quoted examples of cognitive tools for language learning are concordancers and authoring tools for creating class-based learner dictionaries or similar data-bases. These will be described in greater detail later on. Quite often this way of integrating the use of new technologies into language learning necessitates the exploitation of tools which originally were not designed for the learning of languages but with regard to learning tasks in general. An interesting example of this is MindManager, a tool for collecting thoughts and organising content. When advertising this package, recent catalogues actually do refer to its potential applicability in innovative learning scenarios for vocabulary building. The use of word processors with appropriate add-on features, such as integrated dictionaries or style-checkers is another example. In addition, word processors with integrated templates for thought collection or brainstorming and organizing ideas and vocabulary as part of text production tasks is a further possibility of putting into practice a tools-based approach to materials design very much in line with the theoretical framework discussed above.

Such a concept goes somewhat further than just using any tools, such as electronic encyclopaedias or pure word processors as part of the learning process. It entails the principle that any material we provide learners with should be open and flexible, but should also provide learners with a frame to assist them in structuring and co-ordinating acts of knowledge construction. Templates can be designed in the format of advanced organisers as well as tools and tasks which encourage on-the-fly recording of thoughts and impressions while examining learning materials.

Such templates provide ,the potential for students to reorganise or revise their thoughts to better 'make sense' of what they see and hear. Students are able to document their emerging ideas in support of an investigation or problem solving exercise whilst viewing different media. This provides support 
in the formulation of new schemata in the process of accommodating the new information. " (Harper, 1996) In my opinion, the principle function of template-based learning is to provide a framework for gathering information, stimulating recall of prior knowledge, and for guiding processes of knowledge construction, a concept visualised by the following graph:

\section{Materials}

However, looking at the kind of materials currently available for Uzbek language learning, it must be said that the market is still dominated by a large number of traditional computer-based training packages. This kind of software is best described by metaphors such as drill \& kill or grammar hammer. There is still too much of the instructional kind and too few of the learning tools or edutainment type available. Publishers all too often rely on designing impressive multimedia enhanced packages which hide the fact that most of the interactions provided are an adaptation of simple traditional exercise formats to an electronic platform. The large number of vocabulary drills, multiple choice and gap-filling exercises or similar tutorial formats bears witness to the fact that this is true for materials on CD-ROM as well as, more recently, online packages distributed via the internet. Quite often, technical considerations and the power of multimedia features dominate the design of technology enhanced materials for language learning. Multimedia options, such as sound, picture, animation, and video are in a number of instances integrated into courseware not because such features are needed for a learning purpose or in order to assist the acquisition of specific skills, but simply because it gives the product a sexier, more attractive look(Scott, 2009).

When evaluating such courseware, which no doubt has its place somewhere in a technology enriched learning environment, we need to consider whether originally traditional and inflexible exercise formats have been converted into truly exploratory exercises and make use of computer-specific interface features such as drag \& drop, which allow for more innovative learning. Also, the integration of multimedia features with a view to truly enhancing the learning process or to developing specific skills (e.g. listening or viewing comprehension) is a criterion for distinguishing innovative courseware from simple drills. In addition, a user interface which allows for experiment and exploration - both highly constructivist activities - is a sign of quality as are context-sensitive feedback and help options relevant to the learning task as well as user-friendly navigation features. A suitable descriptor for what the world of educational publishing unfortunately still refers to as instructional design could be Florin's suggestion (1990) referred to above, calling for the creation of information landscapes, of virtual towns, or intellectual amusement parks. Such materials could then lead to the acquisition not just of factual knowledge but also of strategic and systemic competence with regard to languages.

\section{Technology Enhanced Materials for Language Learning: A Typology}

The points raised so far seem to suggest that the value of existing materials for language learning purposes is rather limited. There are, however, a number of areas and language learning contexts within which new technologies are being used successfully. These can be classified into five types and will be described in the following:

\section{EXercise MATerials FOr Self-StUdy And SElf ACCESS}

As stated above, the vast majority of technology enhanced materials for Uzbek language learning still follows the footsteps of traditional, workbook-style exercises for self-study. In fact, this seems to be the type of material which automatically comes to mind when teachers are asked about the potential contribution of new media to language learning. Such materials usually package existing exercise formats into an interactive multimedia-enhanced platform.

Apart from the usual tutorial diet, tasks that deal with matching, text reconstruction and text manipulation exercises offer additional kinds of learning activities more in line with innovative methodology. Quite often computer-specific forms of interaction, such as drag \& drop are used to provide more exploratory learning modes. One such task, for example, is listen \& act: a picture and a number of objects are presented on the screen; based on a listening text or instructions given orally by the machine, learners have to grab items and either place them at the appropriate spot on the picture or rearrange items and objects on the picture itself.

The content of the listening task in such exercises is extremely important and must go beyond the scope of simple comprehension questions. Good packages require constant attention by the learner, 
and usually two or three facts or bits of oral information in conjunction with the visual information on the screen need to be considered in order to successfully complete a set of tasks. In addition to such exercises focussing on specific skills, a number of such self-study materials make use of the adventure-game mode. Who is Oscar Lake? or Adventure in Mean City are well-known examples, where - among other types of interaction - branched dialogues are used to provide input for language learning within the format of a detective game.

Most of the self-study materials make use of multimedia components either to provide a situational frame for the learning task or to assist navigation. In addition, sound, image, animation, and video are used to visually enhance help options and feedback provided within a tutorial interaction. Furthermore, sound files are used to train specific skills, such as listening comprehension and pronunciation or to help learners develop an understanding of spoken language and its representation in written form. With regard to this, more recent materials make use of the latest voice-recognition technology. Also, a number of new developments already integrate the internet and e-mail into the learning tasks either by asking learners to search the web via prepared links for background information on a given task or by using e-mail as a communication channel within a (virtual) learner group or with an online tutor. More recently, quite a number of learning materials of the self-study type have been placed on the web; such materials offer a synchronous learning mode with online interaction and feedback.

\section{Authoring Tools}

A second type of the materials under discussion - closely linked with the first type - are so-called authoring tools. Such packages basically provide teachers with ready-made templates for most of the exercise types and interactions commonly used in self-study packages. These templates can then be filled with content and the authoring tool automatically "creates" an interactive exercise using this input. It is important to note that the creation of self-study exercises specifically geared towards a particular target group can be achieved without any knowledge of programming or script-writing, as would be the case when using programming tools such as TOOLBOOK or MACROMEDIA DIRECTOR.

Basic computing skills are sufficient even to enable the integration multimedia features into exercises. A classic example of authoring tools for language learning is the WIDA Software Authoring Suite; a more recent example with additional and more flexible options for putting together complete and structured multimedia enhanced learning packages is the TELOS package. The Half-baked Potatoes package, another example of software which is downloadable free of charge off the internet (http://web.uvic.ca/hrd/halfbaked/), allows teachers to create an interactive learning environment for self-study and to place it on the web.

A number of teachers make use of such tools to create exercises with a view to providing their learners with more effective tasks in the form of electronic homework. However, if one intends to exploit new technologies within a more constructivist framework, such tools can also be used to engage learners in the creation of exercises for their peers. A number of colleagues have reported on their positive experiences with learner groups, where at the end of a unit dealing with a specific set of grammatical rules or lexical items learners do not simply work through a few exercises in order to fully internalise a rule but are invited to work further on the items in a truly task-based mode, using the authoring mode of the tools discussed here.

By asking learners to create an exercise dealing with what has been learned at the conclusion of a unit, one can provide them with a framework within which they have to consider the rule in more detail, think about and search for suitable samples and tasks as well as potential areas for mistakes and contemplate the necessary feedback to be integrated into an exercise. In such cases, learners do work on their linguistic skills but at the same time develop what has been referred to above as language awareness and learning competence.

\section{Electronic Publications and Resources}

Electronic publications in any shape or form are the third type of material that can contribute to a rich learning environment for languages. As up-to-date and topical material is very important for language learning, encyclopaedias on CD-ROM or electronic editions of newsstudys and other publications are of the utmost value for language teachers. Such resources offer a wealth of authentic material which is 
also useful for integrating additional intercultural and political information on the country or countries where a target language is spoken into the learning process. The added value of using electronic resources is manifold: using appropriate search engines or portals, it is quite easy to find interesting texts on the web; and as all materials are made available in a digital format, it is quite easy to adapt texts and other resources for classroom use or specific target groups.

In addition, the use of such resources can be transferred into more flexible learning arrangements, e.g. within the context of project-based learning. As far as such projects are concerned, samples of good practice are published both in print (Kallenbach\& Ritter, 2000) or on servers and portals maintained by educational institutions or associations.

\section{Tools for Processing and Adapting Materials for Classroom USe}

When it comes to the exploitation of authentic resources for classroom use, texts and other materials often need to be adapted in length, level of difficulty, etc. Also, teachers need to convert such texts into worksheets and study-based exercises. A number of tools have recently been offered by educational publishers which combine the flexibility of word processors with prepared routines for analysing and adapting such texts for use with specific target groups. These add-on features are somewhat similar to the kind of macros one can create within most word processing software to automate routine operations, but go a lot further than these.

Tools, such as Toolbox or Text Aktiv and similar software, have the following features in common: they analyse a text with regard to language items or structures they contain; they offer an option for checking the level of difficulty (e.g. unknown vocabulary) against a database consisting of common text books or self-compiled materials; they provide a processing tool which creates worksheets out of texts. The last feature in particular is of great interest for teachers who want to broaden the scope of the materials used in their classes. Usually, two kinds of exercise sheets can be created. The first creates traditional exercises using a gap-filling format and dealing with common linguistic features such as prepositions, adverbs, adjectives and so on. The second uses a text-jumbling or letter-jumbling format to create exercises which engage learners in tasks dealing with reading skills and aspects of cohesion and congruence in texts, again focussing on both linguistic and strategic competencies.

\section{Cognitive Tools: Concordances AND DATA-DRIVEN LEARNing}

When it comes to finding innovative examples of the use of new technologies in language learning, any tool that allows for the creation of discovery-based and exploratory learning materials must rank very highly within a typology of TELL software. One such tool is concordancing software, originally developed as a device to assist research in corpus linguistics. Such a tool can be used with any textual corpus, i.e. a potentially unlimited number of texts compiled into a database. Its basic function is to extract lists with sample contexts of any word or structure entered into the search option:

Such lists can then be used as a basis for what Tim Johns (2010) refers to as data-driven learning. Considering the example above, a learners' task linked with such a selection of concordances would be for them to deduce themselves the exact difference in meaning, connotation, and grammatical features with regard to the verbs look, see, and watch. Grammatical rules can be acquired in such a discovery-based or exploratory mode, e.g. on the basis of lists with concordances of adverbs, offering learners the opportunity to discover rather than to be taught a rule concerning adverbs and word order in English sentences. Tim Johns provides a complete website with samples and links on data-driven learning (http://web.bham.ac.uk/johnstf/timconc.htm). In addition, Chris Tribble (2014) has published an interesting manual on Using Concordances in the Classroom.

When looking at the examples quoted in Tribble's publication or on Tim Johns' website, it becomes apparent that the use of concordancing tools in language learning comes very close to putting into practice some of the theoretical principles discussed at the outset of this study. Grammatical rules and the meanings of words are not simply learned but constructed by the learners themselves, thus enabling learners to develop language awareness in addition to a structural knowledge of sets of meanings.

\section{Telecommunications}

The last aspect to be discussed in this study is not actually a type of tool in itself but rather affects most of the other types and applications mentioned above. Obviously, telecommunications is seen by 
many as the major medium for distributing learning materials in the future as well as for creating a more flexible organisational framework for learning by means of virtual learning groups and telecooperative tutoring. As far as language learning is concerned, the internet and e-mail have already been established as a medium for learning well beyond the exploitation of online resources for classroom use. E-mail is used to integrate authentic stimuli for communication into the curriculum. Electronic pen-pals and multinational project groups and learning partnerships using e-mail and the web for cooperative learning are examples of this. In addition, the use of chat rooms and multi-user domains (MUDs or MOOs) is currently being experimented with in view of their potential for language learning.

Also, a number of Internet Cafés for language learning are already available on the web (c.f. Dave's ESL Caféat http://www.eslcafe.com/), where teachers and learners will find materials and support as well as a platform for communicating in a target language. A further example is the transfer of tandem learning onto a telecommunication platform, where partnerships between language learners are formed and supported by a special server at Bochum University. This also contains a section which describes the principles of tandem-based language learning in more detail.

A very important aspect when looking at the potential of new technologies and telecommunications not just for language learning but also for the development of intercultural competence is the exploitation of such resources for project work that goes beyond the actual classroom. ReinhardDonath (2014) has described a variety of projects which focus on this. Again, knowledge construction rather than formal instruction and co-operation in a (virtual) international team are more in line with developing language competence suitable for the knowledge society than traditional instructivist modes of teaching and learning. In addition, process-oriented learning focussed on a joint product, often published on the internet, is also a tremendous motivation for learners to engage in language learning. The topics dealt with in the context of such projects range from political and historical themes, such as the Northern Ireland Peace Process, Native Americans, and New Englandwhere the old meets the new, to cultural topics, e.g. literature (there are some interesting websites created by learners of English on Paul Auster or Kurt Vonnegut, to name but two examples), and the joint analysis of pop songs or video clips.

\section{PeRspectives}

At this moment in time it is rather difficult to assess the perspectives and future trends in the use of new technologies in foreign language learning. Obviously, most educational publishers and software developers are currently experimenting with a variety of formats.

The world wide web is being considered both in terms of a delivery system for materials as well as in terms of a platform for communicative and interactive learning opportunities. As far as such activities are concerned, the University of Essen is involved in a project setting up a Virtual Language Centre in co-operation with an educational publisher. Also, quite a number of virtual resource centres both for teachers and for learners are being set up on the internet. The Council of Europe is financing a project dedicated to establishing such a resource centre for vocationally oriented language learning.

A further focus of recent developments, which can be observed when looking at the type of development projects financed by the European Union or national authorities, is learnware which focuses on specific skills or addresses strategic competence with a learning-to-learn aim. One such project is Airline Talk, a software package that combines language learning with training specific communicative skills needed by airline staff both on the ground and in the air. The Delta Concept is a further example of such learnware, dealing with negotiating and communication skills in a business environment. Such packages make use of discovery-based multimedia-enhanced learning opportunities to a much larger extent than some of the materials of the traditional self-study type mentioned above.

A further example is a material geared towards assisting learners in the acquisition of specific learning strategies needed for foreign languages. This software, entitled READERS, was developed jointly by the applied linguistics sections of the English departments at Wuppertal and Essen Universities and financed by the North Rhine-Westphalian Ministry of Research \& Education. The READERS software is a reading comprehension package on CD-ROM which goes a lot further than traditional courseware. The main focus of this package is not exercises checking on whether a learner has understood a reading passage. The intention of the software is rather to make learners aware of the kind of strategies that can be employed to facilitate text comprehension. Using interactive animations, 
mental operations are presented that might be helpful when confronted with unknown or seemingly difficult vocabulary, phrases, or paragraphs, and the effectiveness of such mental operations (i.e. strategies) can be experienced by means of task-based exercises.

The software basically presents learners with a number of models for mental interactions with written texts and thus presents a kind of template for each of the strategies considered useful in the processing of text in a foreign language. These models can be defined in terms of templates for mental activities on which learners can model their handling of unknown reading materials, e.g. in a professional context. Initial observations of learners using such materials show that they actually help them to broaden their strategic competence and language awareness. Thus, the development of technologyenhanced tools in the form of strategy trainers might be one direction to pursue when working on new concepts for TELL materials that truly exploit new media in all their flexibility.

On a technical level, additional impetus can be expected from two more recent developments. Obviously, digital speech- and voice-recognition technologies will lead to new types of courseware which offer voice control or so-called voice-pilot features to navigate through a system as well as innovative exercises dealing with pronunciation and speaking skills. Furthermore, the advent of DVD (Digital Versatile Disk) is a very promising technical development which might lead to more flexible multimedia resources that lend themselves more easily to exploitation in learning scenarios focussed on knowledge construction rather than on traditional instruction. And finally, more powerful telecommunications networks will allow for flexible organisational frameworks for language learning by integrating both virtual and person-to-person sessions into truly interactive telecooperative environments for learning.

\section{Conclusion}

The Uzbek language like many languages have not adopted the use of digital technology as a pedagogy. This paper has shown how the tremendous changes initiated by the new technologies necessitate a re-thinking of the way we teach and learn Uzbek language and other languages. This is particularly true for language learning, as language and intercultural competencies are of extreme importance for living and working in the knowledge society. The teaching of Uzbek language as L2 we postulate will be highly enhanced. A growing demand for language learning, however, cannot be met by courses and software following a traditional, behaviourist and instructional methodology. It is argued that a constructivist paradigm for learning focussing on learning in terms of knowledge construction rather than knowledge transmission is better suited for a kind of language learning that leads to the development not only of communicative and structural skills but which also integrates language awareness and learning competence as equally important aims into its curriculum.

Following an assessment of the current state-of-the-art of Technology Enhanced Language Learning, a typology of the kind of technologies and media available for language learning in terms of courseware, tools, and other resources was presented. It was demonstrated how traditional materials for self-study need to integrate more flexible and exploratory learning options, and how authoring tools might also be used within the knowledge-construction type of learning activities. Electronic publications and similar resources, available both offline on CD-ROM and online via the internet were discussed in conjunction with the kind of tools needed for processing and adapting content extracted from such materials for classroom use. However, a description of concordancing software and similar tools has shown that those cognitive tools which allow for the creation of discovery-based and exploratory materials rank very highly within a typology of TELL materials. Telecommunications as well as some of the more recent trends and developments both on the courseware and the technological levels were discussed towards the end of this study.

In summary, it must be stated that over the past decade, language learning theory has seen a shift from a highly guided to a more open learning environment, with constructivism as a new and very much learner-centred paradigm for learning. Learning is seen as a self-structured and self-motivated process of knowledge construction and the learner is regarded as a self-governed creator of knowledge. In addition to the undeniable need to achieve instructional goals, the development of cognitive and strategic abilities suitable for the knowledge society is defined as one of the principle aims of a learning process based on knowledge construction and discovery learning. As far as new technologies and their use in language learning are concerned, this study has shown that technology enhanced materials do have a lot of potential to assist the process of innovation which is needed in this field as 
much as in any other area of education. However, in order to achieve this aim, such materials need to be made use of less in a role as instructional systems and exploited more in a role as tools for teaching and learning.

\section{ACKNOWLEDGEMENT}

This article has been funded by Hankuk University of Foreign Studies Research Fund of 2016

\section{REFERENCES}

Costa, A. \& Liebmann, R. (1995). Process is as important as content. Educational Leadership 52 (6), 23-24.

Donath, R. (ed.) (2014). Das Transatlantische Klassenzimmer: Tips und Ideen für Online-Projekte in der Schule. Hamburg: Körber.

Florin, F. (1990).Information Landscapes. In S. Ambron, \& K. Hooper, (Eds), Learning with Interactive Multimedia. Redmond: Microsoft, 28-49.

Harel, I. \&Papert, S. (1991). Software Design as a Learning Environment. In Papert, S. \&Harel, I (Eds.). Constructionism. Norwood, N.J.: Ablex.

Harper, B. (1996).Using cognitive tools in interactive multimedia. http://www.itu.arts.su.edu.au/ AUC\%C4/Harper.html (3. April 2000)

Johns, T. (2010). From printout to handout: grammar and vocabulary teaching in the context of datadriven learning. In Odlin, T. (ed.). Perspectives in Pedagogical Grammar. Cambridge: CUP, 293313.

Jonassen, D. H. \& Reeves, T. C. (1996). Learning with Technology: Using Computers as cognitive tools. In D. H. Jonassen, (Ed.), Handbook of Research on Educational Communications and Technology.New York: Macmillan, 693-719.

Kallenbach, C. \& Ritter, M. (Eds.). Computerideen für den Englischunterricht. Berlin: Cornelsen.

Little, D., Devitt, S. \& Singleton, D. (1989).Learning Foreign Languages from Authentic Texts: theory and practice. Dublin: Authentik.

Papert, S. (1980). Mindstorms. New York: Basic Books.

Papert, S. (1991).Situating Constructionism. In Papert, S. \& Harel, I (eds.), Constructionism. Norwood, N.J.: Ablex.

Roblyer, E., Havriluk, M.D., Edwards J., \& Havriluk, M. A. (2014).Integrating Educational Technology into Teaching. Upper Saddle River NJ: Merril

Rüschoff, B. (1999). Construction of Knowledge as the Basis for Foreign Language Learning. In Mißler, B. \& Multhaup, U. The Construction of Knowledge, Learner Autonomy and Related Issues in Foreign Language Learning: Essays in Honour of Dieter Wolff.Tübingen: Stauffenberg.

Rüschoff, B. (1999). Wissenskonstruktion als Grundlage fremdsprachlichen Lernens. Fremdsprachen Lehren und Lernen (28), 32-43.

Rüschoff, B. \& Wolff, D. (1999): Fremdsprachenlernen in der Wissensgesellschaft: Zum Einsatz der Neen Technologien in Schule und Unterricht. München:Hueber.

Schwarz, M. (1992). Einführung in die kognitive Linguistik. Tübingen: Francke.

Scott, Ph. (2009). A constructivist view of learning ant teaching science. Children's Learning in Science Project, Centre for Studies in Science and Mathematics Education. Leeds: University of Leeds, UK.

Tribble, C. \& Jones, G. (2014). Concordances in the Classroom. Houston, TX.: Athelstan.

Van Lier, L. (1996). Interaction in the Language Curriculum: awareness, autonomy \& authenticity. London: Longman.

\section{AUTHOR'S BIOGRAPHY}

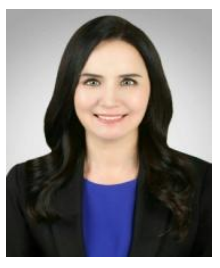

Prof. Aziza Mashrabbekova, holds a PhD in Philology from the National University of Uzbekistan (2000). She is currently an Associate Professor in the Department of Central Asian Studies, College of International and Area Studies, Hankuk University of Foreign Studies in the Republic of Korea. Her main research interests are in Techniques of teaching foreign language and Comparative linguistics. 